\title{
Individual differences in thermoeffector function in the heat: morphological variations help determine effector activation
}

\author{
Sean R Notley, Joonhee Park, Kyoko Tagami, Norikazu Ohnishi, Nigel AS Taylor \\ From 15th International Conference on Environmental Ergonomics (ICEE XV) \\ Portsmouth, UK. 28 June - 3 July 2015
}

\begin{abstract}
Introduction
It is possible that much of the inter-individual variability observed within human thermoeffector responses can be explained by differences in body morphology, specifically the ratio between surface area and mass. However, few have examined these relationships across a sufficiently wide range of body sizes, while controlling for the factors that can independently alter heat dissipation. This investigation was aimed at identifying the proportion of thermoeffector variability that could be explained on the basis of morphology within individuals of widely different surfacearea-to-mass ratios, but of similar age, fitness and adiposity.
\end{abstract}

\section{Methods}

Thermoeffector responses were examined in 36 males with pronounced difference in their surface area-tomass ratio (range: $232.3-292.7 \mathrm{~cm}^{2} \cdot \mathrm{kg}^{-1}$ ). Subjects completed two trials, both under temperate-dry conditions $\left(28^{\circ} \mathrm{C}\right.$; $30 \%$ relative humidity). On separate days, participants completed $20 \mathrm{~min}$ of seated rest, then performed 45 min of steady-state, semi-recumbent cycling at a matched internal heat production rate (metabolic heat external work) for each subject equal to $\sim 135 \mathrm{~W} . \mathrm{m}^{-2}$ (trial one) or $\sim 200 \mathrm{~W} \cdot \mathrm{m}^{-2}$ (trial two), followed by a $20-\mathrm{min}$ seated recovery. Deep-body and skin temperatures, wholebody sweat rate (change in body mass) and local sweat secretion (hand, forearm, upper back and forehead; ventilated capsules) and skin blood flow (forearm and finger; plethysmography) were measured (final $5 \mathrm{~min}$ of exercise). Multiple regression analyses were performed to evaluate the relationship between the change in mean body temperature $\left(\Delta \mathrm{T}_{\mathrm{b}}\right)$ and surface-area-to-mass ratio on skin

* Correspondence: nigel_taylor@uow.edu.au

Centre for Human and Applied Physiology, School of Medicine, University of Wollongong, Wollongong, Australia

\section{Discussion}

Whilst phenotypic (endurance training, heat acclimation) and genotypic differences modulate the level of steadystate skin blood flow and sweating, a significant, albeit modest, amount of that variation during light exercise (trial one) can be explained by an individual's surfacearea-to-mass ratio. However, when the work rate was increased (trial two), now forcing a greater reliance upon evaporative cooling, the surface-area-to-mass ratio became a principal determinant of whole-body sweat rate.

\section{Conclusion}

These data indicate that variations in thermoeffector function during steady-state exercise can be explained 
on the basis of morphological configuration during moderate thermal strain. These observations lead one to hypothesise that heat-related gender differences, and preferential changes in effector function during heat adaptation, might also be explained by differences in body morphology.

Published: 14 September 2015

doi:10.1186/2046-7648-4-S1-A102

Cite this article as: Notley et al:: Individual differences in thermoeffector function in the heat: morphological variations help determine effector activation. Extreme Physiology \& Medicine 2015 4(Suppl 1):A102.

Submit your next manuscript to BioMed Central and take full advantage of:

- Convenient online submission

- Thorough peer review

- No space constraints or color figure charges

- Immediate publication on acceptance

- Inclusion in PubMed, CAS, Scopus and Google Scholar

- Research which is freely available for redistribution

Submit your manuscript at www.biomedcentral.com/submit 